\title{
Clinical changes of TMD and condyle stability after two jaw surgery with and without preceding TMD treatments in class III patients
}

Sang-Yong Yoon, Jae-Min Song, Yong-Deok Kim, In-Kyo Chung, Sang-Hun Shin ${ }^{*}$ and Pusan Korea Pusan National University

\begin{abstract}
Background: This study are to identify the symptomatic changes and condylar stability after 2 jaw surgery without preceding treatments for Temporomandibular joints(TMJ) in class III patients with the TMJ symptoms; and to assess therapeutic effect of 2 jaw surgery and the necessity of preceding treatment for alleviation of TMJ symptoms.

Methods: 30 prognathic patients with preexisting TMJ symptoms were divided into 2 groups according to presence or absence of preceding treatments before the surgery. We evaluated symptomatic changes on both TMJ by questionnaires and clinical examinations. And we reconstructed 3D cone beam computed tomography images before 2 jaw surgery, immediately after the surgery, and 6 months or more after the surgery with SimPlant software, and analyzed the stability of condylar position on 3D reconstruction model. Significances were assessed by the Wilcoxon signed rank test on SPSS ver. 20.0.
\end{abstract}

Results: Both groups had favorable changes of TMJ symptoms after orthognathic surgery. And postoperative position of condyle had good stability during follow-up period.

Conclusion: 2 jaw surgery without preceding treatments for TMD can have therapeutic effect for TMD patients with class III malocclusion.

Keywords: Orthognathic surgery; 2 jaw surgery; TMJ; Condylar stability; TMD

\section{Background}

Many patients with dentofacial deformity often have various symptoms and signs on temporomandibular joints (TMJ) and its related structures. The symptoms and signs of temporomandibular disorders (TMD) typically include: (1) Pain during resting, palpation or joint movement, (2) TMJ noise such as clicking, popping, and crepitus, (3) Joint dysfunction such as limitation of mouth opening (LOM), jaw locking, and jaw deviations. TMD can be the manifestation of multifactorial dysfunction in oral and maxillofacial area [1], and the occlusion accounts for only a small portion. McNamara et al. [2] expected that the contribution of occlusal factors to TMJ symptoms is only $10 \sim 20 \%$.

\footnotetext{
*Correspondence: ssh8080@pusan.ac.kr
Department of Oral and Maxillofacial Surgery, School of Dentistry, Pusan
National University, 49 Busandaehak-ro, Mulgeum-eup, Yangsan 626-870,

* Correspondence: ssh8080@pusan.ac.kr
Department of Oral and Maxillofacial Surgery, School of Dentistry, Pusan
National University, 49 Busandaehak-ro, Mulgeum-eup, Yangsan 626-870,

* Correspondence: ssh8080@pusan.ac.kr
Department of Oral and Maxillofacial Surgery, School of Dentistry, Pusan
National University, 49 Busandaehak-ro, Mulgeum-eup, Yangsan 626-870, Korea
} ment to resolve severe skeletal discrepancies through surgical corrections of maxillomandibular complex, and can change the congenital interocclusal relationship and condylar position. Many studies have been reported various degree of improvement, deterioration or no effect in symptoms and signs of TMD after orthognathic surgery [3-13]. Recently, it is generalized that there is no contraindication related with TMD in orthognathic surgery except for acute symptoms or inflammatory diseases on TMJ. But there is still controversial about the necessity of preceding treatment for stabilization of preoperative TMJ condition.

The purpose of this retrospective study are (1) to identify changes of clinical symptoms and signs and postoperative stability of condyle according to presence or absence of preceding treatments in 2-jaw surgery patients with prior TMD, and (2) to evaluate 
the necessity of preceding treatment for alleviation of TMD.

\section{Methods \\ Subjects}

The initial subjects consisted of 54 patients (18 males and 36 females) who complained of TMD before 2-jaw surgery. Inclusion criteria were: 2 -jaw surgery by Le Fort I osteotomy and bilateral sagittal split ramus osteotomy (BSSRO), no history of orofacial trauma, check-up with cone beam computed tomography (CBCT) imaging at 3 periods (T0: preoperative period, $\mathrm{T} 1$ : postoperative 1 week or less, T2: postoperative 6 months or more). Exclusion criteria were: congenital developmental disorders such as cranio-facial syndromes and clefting, inflammatory TMJ disease such as acute capsulitis and osteoarthritis. On the basis of the criteria, 32 patients were recruited finally. The patients were divided into two groups according to presence or absence of preceding treatments for the purposes of alleviation of TMD and stabilization of condyles before the surgery: The study group consisted of 15 patients that had no preoperative TMD treatments (sex: 4 males and 11 females, mean age: $24.8 \pm 2.76$ years, range: $21-31$ years). And the control group consisted of 15 patients had been treated until the symptoms and signs of TMD alleviated (sex: 7 males and 8 females, mean age: $24.4 \pm 4.29$ years, range: 18 31 years). The treatments for stabilization of preoperative TMJ condition included medication therapy, physical therapy, splint therapy, and self-regulation therapy. This study was exempted by the Institutional Review Board at Pusan National University Dental Hospital, and we followed the guidelines of Helsinki Declaration in this study.

\section{Surgical procedure}

All patients underwent 2-jaw surgery by 1 experienced surgeon from January, 2007 to June, 2012 in the clinic of Oral and Maxillofacial surgery, Pusan National University Dental Hospital. During the BSSRO, the mandibular proximal segments were manually repositioned and fixated with single miniplate (4 holes) \& four monocortical screws (2.0 mm diameter) through intraoral approach. Intermaxillary fixation with the occlusion guided wafer was applied for 1 week after the surgery. Since the 1 week, the postoperative physical trainings for mandibular function were progressed gradually.

\section{Clinical examination of TMD}

In this study, we collected the data by self-reported questionnaires and clinical and functional examinations: (1) TMJ pain during function(mouth opening or mastication), (2) TMJ noise on jaw movement, (3) LOM under $35 \mathrm{~mm}$. The study group were examined in three times: before the preceding treatments for TMD, before surgery and 6 months after surgery. The control group were examined in two times: before surgery and 6 months after surgery. Self-reported questionnaire consisted of several questions regarding the subjective changes of TMJ symptoms. Clinical and functional examinations were performed for the diagnosis of TMD according to the Research Diagnostic Criteria for TMD (RDC/TMD) Axis I [14]. The severity of TMJ pain and noise was rated on Numerical Analogue Scales (NAS) composed of 11 rating points. The NAS ranged from 0 to 10 with 0 indicating 'no symptom and sign', 10 representing 'worst possible symptom and sign', and 5 documenting an intermediate level at 'moderate symptom and sign'. The change of LOM was evaluated as three grades: 'improvement $(+)$ ', 'deterioration $(-)$ ', and 'no change (0)'.

\section{Analysis of condylar position with 3D CBCT}

The patients underwent 3D CBCT imaging with the closed mouth (Pax-Zenith 3D, VATECH, Korea). For ascertainment of positional changes in both condyles, dental CBCT (DCT) images were reconstructed with 3D dental image software (SimPlant Pro Crystal for Intel X86 Platform V13. 0. 1. 4, Belgium). On the basis of three reference planes and twenty-five reference points set up on 3D reconstruction model, fifteen measurements were obtained (Figures 1 and 2, Tables 1 and 2).

\section{Statistical methods}

The data were analyzed with a commercial statistical software package (SPSS for windows ver. 20.0). Significances of differences between the times were assessed by the Wilcoxon signed rank test. The significant level is set at $P<0.05$.

\section{Results}

\section{Changes of clinical TMJ symptoms}

Changes between preoperative and postoperative TMJ symptoms in 30 orthognathic patients are summarized (Tables 3, 4, 5 and 6). The significances of symptomatic changes after orthognathic surgery are analyzed statistically, but the statistical process of LOM was excluded because LOM was rare in patients (Table 7).

\section{Study group (patients without preoperative treatments for TMJ symptoms)}

Ten patients (66.7\%) experienced TMJ noises without TMJ pain before orthognathic surgery, and there were decrease to 6 patients (40\%) after the surgery. 5 patients (33.3\%) reported both TMJ pain and noise before the surgery were reduced to 2 patients (13.3\%) after the surgery and those with no symptom increased from none to 7 (46.7\%). The average scores of TMJ pain and noise 

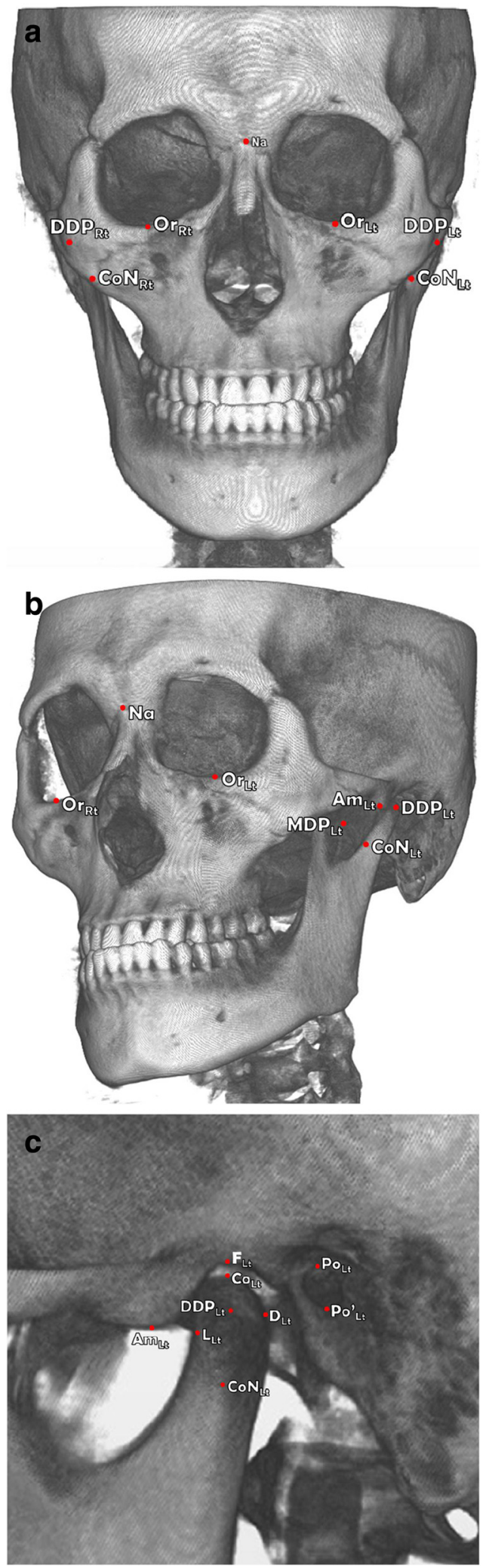

Figure 1 Reference points on 3D reconstruction model.

a. Coronal view; b. Oblique view (Left); c. Sagittal view (Left).
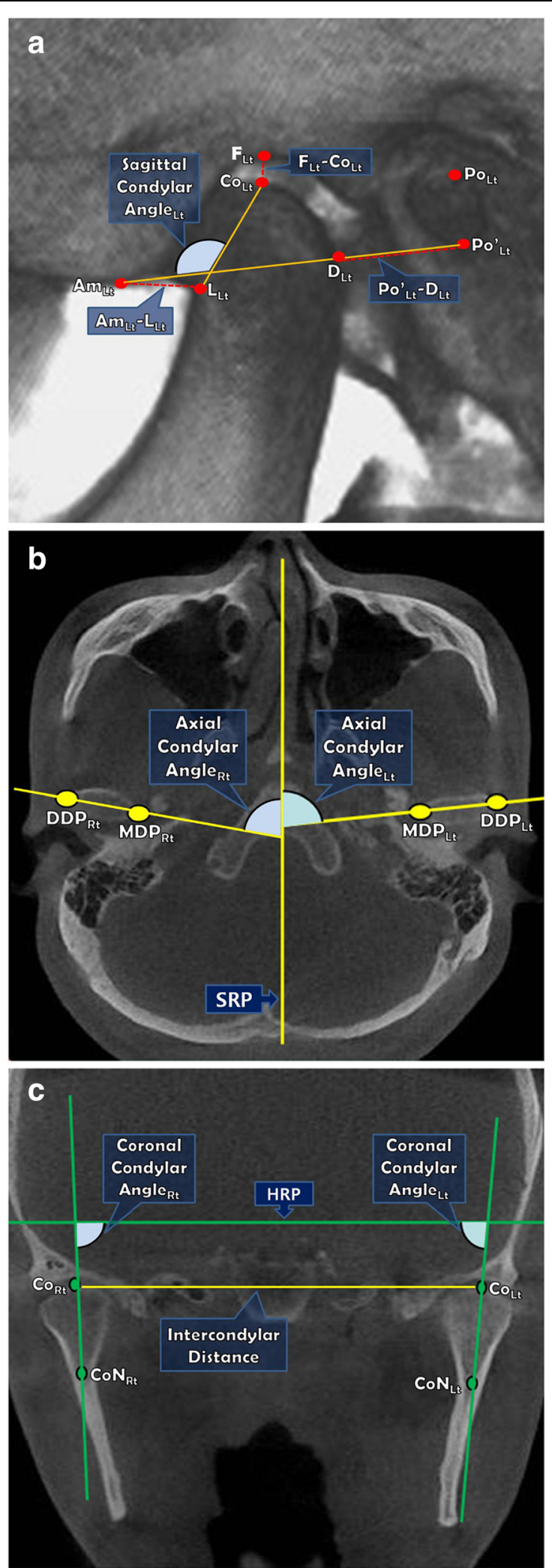

Figure 2 Measurements on 3D CBCT images. a. Sagittal view (Left); b. Axial view; c. Coronal view. 
Table 1 Definitions of reference points \& planes

\begin{tabular}{|c|c|}
\hline Reference planes & Description \\
\hline \multicolumn{2}{|l|}{ A. Reference planes } \\
\hline $\begin{array}{l}\text { Horizontal Reference } \\
\text { Plane (HRP) }\end{array}$ & $\begin{array}{l}\text { The plane constructed by Po } \mathrm{P}_{\text {Rt. }} \text { - Or } \mathrm{r}_{\text {Rt. }} \text { - Polt. } \\
\text { (Frankfort plane) }\end{array}$ \\
\hline $\begin{array}{l}\text { Sagittal Reference } \\
\text { Plane (SRP) }\end{array}$ & $\begin{array}{l}\text { The plane perpendicular to FH plane \& passing } \\
\text { through } \mathrm{Na} \text { - Ba line (Midsagittal plane) }\end{array}$ \\
\hline $\begin{array}{l}\text { Coronal Reference } \\
\text { Plane (CRP) }\end{array}$ & $\begin{array}{l}\text { The plane perpendicular to } \mathrm{FH} \text { plane and } \\
\text { Midsagittal plane passing through } \mathrm{Na} \\
\text { ( } \mathrm{Na} \text { - perpendicular plane) }\end{array}$ \\
\hline \multicolumn{2}{|l|}{ B. Reference points } \\
\hline $\mathrm{Na}$ & $\begin{array}{l}\text { The most anterior point of nasofrontal suture } \\
\text { on sagittal plane }\end{array}$ \\
\hline S & The midpoint of the fossa hypophysealis \\
\hline $\mathrm{Ba}$ & $\begin{array}{l}\text { The midpoint on the anterior border of the } \\
\text { foramen magnum }\end{array}$ \\
\hline $\mathrm{F}_{\mathrm{Rt}} / \mathrm{F}_{\mathrm{Lt}}$ & $\begin{array}{l}\text { The most superior point of the (right/left) } \\
\text { glenoid fossa }\end{array}$ \\
\hline $\mathrm{Co}_{\mathrm{Rt}} / \mathrm{CO}_{\mathrm{Lt}}$ & $\begin{array}{l}\text { The most superior point of the (right/left) } \\
\text { condyle }\end{array}$ \\
\hline $\mathrm{L}_{\mathrm{Rt}} / \mathrm{L}_{\mathrm{Lt}}$ & $\begin{array}{l}\text { The most posterior point on anterior surface } \\
\text { of (right/left) condyle }\end{array}$ \\
\hline $\mathrm{Po}_{\mathrm{Rt}} / \mathrm{PO}_{\mathrm{Lt}}$ & $\begin{array}{l}\text { The most superior point of the (right/left) } \\
\text { external auditory meatus }\end{array}$ \\
\hline $\mathrm{PO}_{\mathrm{Rt}}^{\prime} / \mathrm{PO}_{\mathrm{Lt}}^{\prime}$ & $\begin{array}{l}\text { The most inferior point of the (right/left) } \\
\text { external auditory meatus }\end{array}$ \\
\hline$A m_{R t} / A m_{L t}$ & $\begin{array}{l}\text { The most inferior point of (right/left) articular } \\
\text { eminence }\end{array}$ \\
\hline $\mathrm{MDP}_{\mathrm{Rt}} / \mathrm{MDP}_{\mathrm{Lt}}$ & The most medial point of (right/left) disc pole \\
\hline $\mathrm{DDP}_{\mathrm{Rt}} / \mathrm{DDP} \mathrm{Lt}_{\mathrm{Lt}}$ & The most distal point of (right/left) disc pole \\
\hline $\mathrm{CoN}_{\mathrm{Rt}} / \mathrm{CoN}_{\mathrm{Lt}}$ & $\begin{array}{l}\text { The mid-point of (right/left) condylar neck } \\
\text { on coronal view }\end{array}$ \\
\hline $\mathrm{Or}_{\mathrm{Rt}} / \mathrm{Or}_{\mathrm{Lt}}$ & $\begin{array}{l}\text { The most inferior point of the (right/left) } \\
\text { infraorbital margin }\end{array}$ \\
\hline $\mathrm{D}_{\mathrm{Rt}} / \mathrm{D}_{\mathrm{Lt}}$ & $\begin{array}{l}\text { The intersecting point on posterior surface of } \\
\text { condyle and Po - Am line (Right/Left) }\end{array}$ \\
\hline
\end{tabular}

Table 2 Definitions of measurements

\begin{tabular}{|c|c|c|}
\hline Plane & Measurement & Description \\
\hline \multirow[t]{5}{*}{ Sagittal } & $P_{O_{\text {Rt. }}^{\prime}}^{\prime}-\mathrm{D}_{\text {Rt. }} / \mathrm{Po}_{\text {Lt. }}^{\prime}-\mathrm{D}_{\text {Lt. }}$ & Distance between $\mathrm{Po}^{\prime}$ \& D \\
\hline & $\mathrm{F}_{\text {Rt. }}-\mathrm{CO}_{\text {Rt. }} / \mathrm{F}_{\text {Lt. }}-\mathrm{CO}_{\text {Lt. }}$ & Distance between F \& Co \\
\hline & $A m_{\text {Rt. }}-L_{\text {Rt. }} / A m_{\text {Lt. }}-L_{\text {Lt. }}$ & Distance between Am \& L \\
\hline & $\mathrm{Po}_{\text {Rt. }}^{\prime}-\mathrm{Am}_{\text {Rt. }} / \mathrm{Po}_{\text {Lt. }}^{\prime}-\mathrm{Am}_{\mathrm{Lt} .}$ & Distance between Po' \& Am \\
\hline & Sagittal condylar angle $e_{R t / L t}$ & $\begin{array}{l}\text { Angle composed of } C o-L \text { line \& } \\
\text { Po' - Am line }\end{array}$ \\
\hline \multirow[t]{2}{*}{ Axial } & Axial condylar angle $e_{\text {Rt./Lt. }}$ & $\begin{array}{l}\text { Angle composed of MDP - DDP } \\
\text { line \& SRP }\end{array}$ \\
\hline & Intercondylar Distance & Distance between $\mathrm{Co}_{\text {Rt. }} \& \mathrm{Co}_{\mathrm{Lt} .}$ \\
\hline Coronal & Coronal condylar angle $\mathrm{R}_{\mathrm{Rt} / \mathrm{Lt}}$ & $\begin{array}{l}\text { Angle composed of CoN - Co } \\
\text { line \& HRP }\end{array}$ \\
\hline
\end{tabular}

Table 3 Clinical data in both TMJs, A. Distributions

\begin{tabular}{|c|c|c|c|c|}
\hline \multirow[b]{2}{*}{ Symptoms } & \multicolumn{2}{|c|}{ Study group } & \multicolumn{2}{|c|}{ Control group } \\
\hline & T0 & T2 & T0 & $\mathrm{T} 2$ \\
\hline TMJ pain only & $0(0)$ & $0(0)$ & $3(20)$ & $3(20)$ \\
\hline TMJ noise only & $10(66.7)$ & $6(40)$ & $4(26.7)$ & $2(13.3)$ \\
\hline LOM only & $0(0)$ & $0(0)$ & $0(0)$ & $0(0)$ \\
\hline TMJ pain and noise only & $5(33.3)$ & $2(13.3)$ & $6(40)$ & $5(33.3)$ \\
\hline TMJ pain, noise and LOM & $0(0)$ & $0(0)$ & $2(13.3)$ & $0(0)$ \\
\hline No symptoms & $0(0)$ & $7(46.7)$ & $0(0)$ & $5(33.3)$ \\
\hline
\end{tabular}

Numbers of patients (\%).

were 1.5 (range : 0-7) and 4.0 (range : 2-8) on T0. But the scores were decreased to 0.4 (range : 0-4) and 1.2 (range : 0-4) on T2. All TMJs in study group had varying degrees of symptomatic alleviations and no deteriorations in comparison between the T0 and T2. The symptomatic decreases between preoperative and postoperative pain and noise (T0-T1, T0-T2) were significant statistically $(P<.05)$.

\section{Control group (patients with preoperative treatments for TMJ symptoms)}

The number of patients with TMJ symptoms was decreased slightly and the number of patients with no TMJ symptoms was increased from none to $5(33.3 \%)$ in control group. The average pain score was 2.3 (range : 0-7) on T0, and 1.1 (range : $0-4$ ) on T2. The average noise score was reduced from 3.1 (range : 0-5) to 0.9 (range : 0-5) after 2 jaw surgery (T2). Although very few of the patients (2 of 11 patients with TMJ pain and 1 of 12 patients with TMJ noise) reported slight worsening comparing $\mathrm{T} 0$ versus $\mathrm{T} 2$, the majority of the patients were relieved or unchanged. Moreover two patients with preoperative LOM showed improvement unexceptionally. In the results of statistical analysis, changes of TMJ noise between T0 and T2 were statistically significant $(P<.05)$ even though TMJ pain had no significant changes $(p>.05)$.

\section{Changes of condylar position with analysis of $3 \mathrm{~d}$ cbct Surgical change (TO - T1)}

Between T0 and T1, study group had significant changes of $\mathrm{F}_{\mathrm{Rt} .}-\mathrm{Co}_{\mathrm{Rt}}, \mathrm{F}_{\mathrm{Lt} .}-\mathrm{Co}_{\mathrm{Lt}}$, Am $\mathrm{Am}_{\mathrm{Rt} .}-\mathrm{L}_{\mathrm{Rt}}$, Axial Axis angle (Rt.), Intercondylar Distance, and control group

Table 4 Clinical data in both TMJs, B. TMJ pain and noise B-1. Change of NAS values

\begin{tabular}{llllll}
\hline & \multicolumn{2}{l}{ Study group } & & \multicolumn{2}{c}{ Control group } \\
\cline { 2 - 3 } \cline { 6 - 7 } Symptoms & T0 & T2 & & T0 & T2 \\
\hline TMJ pain & $1.5(0-7)$ & $0.4(0-4)$ & & $2.3(0-7)$ & $1.1(0-4)$ \\
TMJ noise & $4.0(2-8)$ & $1.2(0-4)$ & & $3.1(0-5)$ & $0.9(0-5)$ \\
\hline
\end{tabular}

Average (range). 
Table 5 Clinical data in both TMJs, B-2: Symptomatic change of both TMJs

\begin{tabular}{llll}
\hline Symptoms & Change & Study group & Control group \\
\hline \multirow{3}{*}{ TMJ Pain } & Improved & $6(20)$ & $12(40)$ \\
& Deteriorated & $0(0)$ & $4(13)$ \\
& No change & $24(80)$ & $14(47)$ \\
& Improved & $19(63.5)$ & $17(56.5)$ \\
TMJ Noise & Deteriorated & $0(0)$ & $1(3.5)$ \\
& No change & $11(36.5)$ & $12(40)$ \\
\hline
\end{tabular}

Numbers of TMJs (\%).

had significant changes of $\mathrm{F}_{\mathrm{Rt} .}-\mathrm{Co}_{\mathrm{Rt} \text {., }} \mathrm{F}_{\mathrm{Lt} .}-\mathrm{Co}_{\mathrm{Lt} . \text {, }}$ But, other measurements were not changed significantly during 2 jaw surgery.

\section{Postoperative stability (T1 - T2)}

Between T1 and T2, most measurements were not changed significantly after the surgery. Changes of only three measurements $\left(\mathrm{F}_{\mathrm{Rt}}\right.$. $-\mathrm{Co}_{\mathrm{Rt}}, \mathrm{F}_{\mathrm{Lt}}$ - $\mathrm{Co}_{\mathrm{Lt}}$, Intercondylar Distance) were significant in both groups. Intercondylar distance significantly increased immediately after the surgery, but returned near the existing position during follow-up interval.

\section{Definitive change of condylar position (TO - T2)}

The final changes of condylar positions were evaluated from identification of positional changes between T0 and T2. Any measurements of both groups did not have significant changes in this period (Table 8).

\section{Discussions}

Many studies have suggested that surgical corrections of dento-facial deformities can improve the symptoms relating to TMJ pain and dysfunction [3-11]. However, Henrikson et al. [15] suggested that short-term decrease of the painful tenderness may be due to altered activity of the muscles, and Onizawa et al. [16] also speculated that alteration of TMJ sounds after orthognathic surgery were associated with postoperative reduction of mandibular mobility. Unlike these studies, we think that improvements of the TMJ symptoms are not solely due to postoperative reduction of muscular function or jaw mobility and may be relevant to the improvements of

Table 6 Clinical data in both TMJs, C LOM

\begin{tabular}{llll}
\hline Symptom & Change & Study group & Control group \\
\hline LOM & Improved & $0(0)$ & $2(13)$ \\
& Deteriorated & $0(0)$ & $0(0)$ \\
& No change & $15(100)$ & $13(87)$ \\
\hline
\end{tabular}

Numbers of patients (\%).
Table 7 Significance in changes of TMJ symptoms

\begin{tabular}{lccccccc}
\hline Symptoms & \multicolumn{2}{l}{ Study group } & & & \multicolumn{3}{l}{ Control group } \\
\cline { 2 - 3 } & T1-T0 & T2-T0 & T2-T1 & & T1-T0 & T2-T0 & T2-T1 \\
\hline Pain & $.034^{*}$ & $.034^{*}$ & 1.000 & & .241 & .183 & .842 \\
Noise & $.000^{*}$ & $.000^{*}$ & .705 & & $.000^{*}$ & $.001^{*}$ & .886 \\
\hline
\end{tabular}

*Significant difference by Wilcoxon signed rank test $(P<0.05)$.

occlusal, skeletal and neuromuscular balance after the surgery. The aim of this study is to identify postoperative changes of TMD symptoms and condylar stability and to evaluate additional therapeutic effect of the surgery and necessity of preoperative TMD treatments on the orthognathic patients with TMD definitively.

The symptomatic results of this study are almost consistent with previous studies in which TMJ symptoms improved. Ueki et al. [17] found that the incidence of TMJ symptoms decreased after SSRO although SSRO did not change the disk position. According to Togashi et al. [18], the incidence of TMJ signs and symptoms significantly decreased from $29.5 \%$ before orthognathic surgery to $12.1 \%$ at one year after the surgery. Also, TMJ signs and symptoms decreased in $82.4 \%$ of symptomatic patients before the surgery. In this study, both symptomatic patients with and without preoperative TMD treatment had favorable changes of TMJ symptoms. Especially, TMJ noise decreased significantly in both groups. Although deteriorations of the symptoms were unusually shown, TMJ pain generally improved after the surgery. There were significant improvements and no deteriorations in study group, but a few deteriorations and

Table 8 Significances in changes of condylar positions

\begin{tabular}{|c|c|c|c|c|c|c|}
\hline \multirow[t]{2}{*}{ Measurement } & \multicolumn{3}{|c|}{ Study group } & \multicolumn{3}{|c|}{ Control group } \\
\hline & T1-T0 & T2-T1 & T2-T0 & T1-T0 & T2-T1 & T2-T0 \\
\hline$P O_{\text {Lt. }}^{\prime}-D_{\text {Lt. }}$ & .334 & .594 & .233 & .057 & .094 & .100 \\
\hline$P_{O_{R t}^{\prime}}^{\prime}-D_{\text {Rt. }}$ & .589 & .589 & .865 & .140 & .211 & .776 \\
\hline $\mathrm{F}_{\mathrm{Lt} .}-\mathrm{CO}_{\mathrm{Lt}}$ & $.008^{*}$ & $.036^{*}$ & .307 & $.043^{*}$ & $.011^{*}$ & .363 \\
\hline $\mathrm{F}_{\mathrm{Rt} .}-\mathrm{CO}_{\mathrm{Rt} .}$ & $.001^{*}$ & $.009^{*}$ & .058 & $.002^{*}$ & $.036^{*}$ & .147 \\
\hline$A m_{L t .}-L_{L t}$ & .670 & .156 & .156 & .820 & .495 & .394 \\
\hline$A m_{R t .}-L_{R t .}$ & $.001^{*}$ & .233 & .055 & .281 & .427 & .053 \\
\hline$P O_{\text {Lt. }}^{\prime}-A m_{L t .}$ & .733 & .256 & .100 & .551 & .394 & .460 \\
\hline PO Rt. $-A_{\text {Rt. }}$ & .112 & .910 & .191 & .910 & .589 & .820 \\
\hline Sagittal condylar angle (Lt.) & .256 & .331 & .798 & .067 & .256 & 609 \\
\hline Sagittal condylar angle (Rt.) & .078 & .910 & .057 & .733 & .307 & .211 \\
\hline Axial axis angle (Lt.) & .191 & .865 & .100 & .191 & .609 & .100 \\
\hline Axial axis angle (Rt.) & $.035^{*}$ & .910 & .052 & .233 & .650 & .233 \\
\hline Intercondylar distance & $.011^{*}$ & $.032^{*}$ & .334 & .061 & .140 & .100 \\
\hline Coronal axis angle (Lt.) & .712 & .363 & .427 & .609 & .281 & .334 \\
\hline Coronal axis angle (Rt.) & .100 & .650 & .425 & .363 & .443 & .156 \\
\hline
\end{tabular}

*Significant difference by Wilcoxon signed rank test $(P<0.05)$. 
unsignificant changes in control group. We speculated that it is the reason that the control group included some TMD patients with facial asymmetry. The comparison of LOM was little meaningful because of insufficiency of subjects with preexisting LOM.

Condylar repositioning during BSSRO can influence the changes of TMJ symptoms and positional stability of condyle during postoperative follow-up. Individual physiological adaptation also can affect positional changes of condyles during follow-up period. However, according to Nakata et al. [19], the physiological adaptation to the surgically corrected structures needs long time over two years. Because the follow-up time of this study was less than a year, we eliminated a factor of the physiologic adaptation. In this study, the condylar position of both groups during postoperative follow-up interval had good stability $(P>.05)$ except for the distances between glenoid fossa and condyle $(\mathrm{F}-\mathrm{Co})$ in both sides. It seems that whether or not TMD treatments precede 2 jaw surgery in patients with prior TMD did not have any significant influences on postoperative stability of condylar position. We estimated that the significant changes of both F - Co measurements were because all patients in both groups underwent CBCT wearing the occlusal splint at T1 although showed significant changes $(P<.05)$. In other words, we considered them as temporary increases due to wearing of the occlusal splint for preventing skeletal relapse during 1 month or less after the surgery. Intercondylar distance in study group significantly increased immediately after the surgery, but returned near the existing position during follow-up interval. Kim et al. [20] reported that condyle in the glenoid fossa had tendency to return to normal position during postoperative period in orthognathic patients. We used a miniplate and 4 monocortical screws for semirigid fixation so that functional stability and slight flexibility for enhanced long term TMJ function could be achieved [21].

2 jaw surgery can have favorable effects on TMJ symptoms in patients with dentofacial deformities. The results in this study showed that even if TMJ symptoms were not treated before the surgery, 2 jaw surgery could have therapeutic effects for TMJ symptoms while also provide good stability of condyles. This study has some differences from other similar studies. Firstly, we divided orthognathic patients into 2 groups contingent upon presence or absence of preoperative treatment for TMJ symptoms, unlike other studies in which TMJ symptoms concerned as the standard of classification. Secondly, we simultaneously analyzed postoperative stability of condylar position with $3 \mathrm{D}$ CBCT while examining changes of TMJ symptoms. On the other hand, there are also some limitations: (1) The number of the orthognathic patients without any preceding treatments for TMJ symptoms before the surgery were not enough. (2) We had only mandibular prognathic patients with class III malocclusion among various dentofacial deformities. (3) We did not use validated scales such as the modified Helkimo index, craniomandibular index, and the Research Diagnostic Criteria [14,22,23]. We collected only the symptomatic data by simple self-report form.

\section{Conclusions}

This study showed improvements of preexisting TMJ symptoms and good condylar stability during the postoperative follow-up even though the patients were not treated for the TMJ symptoms before the surgery. Thus, We think that 2 jaw surgery patients with preexisting TMJ symptoms can have therapeutic effect exclusively attributed to the surgery unless the existence of acute and severe TMD before the surgery. However, the symptoms cannot be always improved and there would be some risk of symptomatic deterioration though the risk is very quite low.

\section{Abbreviations}

TMJ: temporomandibular joints; TMD: temporomandibular disorders; LOM: limitation of mouth opening; BSSRO: bilateral sagittal split ramus osteotomy; CBCT: cone beam computed tomography; NAS: Numerical Analogue Scales; DCT: dental CBCT.

\section{Competing interest}

The author declared that they have no competing interest.

\section{Authors' contributions}

SYY carried out all processes with other authors. JMS been involved in drafting the many parts of manuscript. YDK involved in revising it critically for all content. IKC made substantial contributions to analysis and interpretation of data. SHS made contributions to conception and design, acquisition of data, analysis and interpretation of data. All author read and approved the final manuscript.

\section{Acknowledgments}

All authors have viewed and agreed to the submission.

This work was supported by a 2-Year Research Grant of Pusan National University, Korea.

Received: 9 January 2015 Accepted: 20 January 2015

Published online: 21 February 2015

\section{References}

1. Luther F (1998) Orthodontics and the temporomandibular joint: where are we now? Part 1. Orthodontic treatment and temporomandibular disorders. Angle Orthod 68:295-304

2. McNamara JA, Seligman DA, Okeson JP (1995) Occlusion, Orthodontic treatment, and temporomandibular disorders: a review. J Orofac Pain 9:73-90

3. White CS, Dolwick MF (1992) Prevalence and variance of temporomandibular dysfunction in orthognathic surgery patients. Int J Adult Orthodon Orthognath Surg 7:7-14

4. Westermark A, Shayeghi F, Thor A (2001) Temporomandibular dysfunction in 1,516 patients before and after orthognathic. Int J Adult Orthodon Orthognath Surg 16:145-151

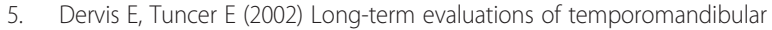
disorders in patients undergoing orthognathic surgery compared with a control group In: United States. 554-560

6. Dujoncquoy JP, Ferri J, Raoul G, Kleinheinz J (2010) Pmc2998459; Temporomandibular joint dysfunction and orthognathic surgery: a retrospective. Head Face Med 6:27 
7. Panula K, Somppi M, Finne K, Oikarinen K (2000) Effects of orthognathic surgery on temporomandibular joint dysfunction. A Int J Oral Maxillofac Surg 29:183-187

8. Karabouta I, Martis C (1985) The TMJ dysfunctionsyndrome before and after sagittal split osteotomy of the rami. J Maxillofac Surg 13:185-188

9. Al-Riyami S, Moles DR, Cunningham SJ (2009) Orthognathic treatment and temporomandibular disorders: a systematic review. In: Part 1. A new qualityassessment technique and analysis of study characteristics and classifications In: . United States., 624 e1,15; discussion 624-5

10. De Clercq CA, Neyt LF, Mommaerts MY, Abeloos JS (1998) Orthognathic surgery: patients' subjective findings with focus on the. J Craniomaxillofac Surg 26:29-34

11. Moenning JE, Bussard DA, Montefalco PM, Lapp TH, Garrison BT (1997) Medical necessity of orthognathic surgery for the treatment of dentofacial deformities associated with temporomandibular disorders. Int J Adult Orthodon Orthognath Surg 12:153-161

12. Aghabeigi B, Hiranaka D, Keith DA, Kelly JP, Crean SJ (2001) Effect of orthognathic surgery on the temporomandibular joint in patients with anterior open bite. Int J Adult Orthodon Orthognath Surg 16:153-160

13. Wolford LM, Reiche-Fischel O, Mehra P (2003) Changes in temporomandibular joint dysfunction after orthognathic surgery In: . United States, 2003 American Association of Oral and Maxillofacial Surgeons. J Oral Maxillofac Surg 61:655-660, 2003: 655,60; discussion 661

14. Dworkin SF, LeResche L (1992) Research diagnostic criteria for temporomandibular disorders: review, criteria. J Craniomandib Disord 6:301-355

15. Henrikson T, Nilner M, Kurol J (1999) Symptoms and signs of temporomandibular disorders before, during and after orthodontic treatment. Swed Dent J 23:193-207

16. Onizawa K, Schmelzeisen R, Vogt S (1995) Alteration of temporomandibular joint symptoms after orthognathic surgery: comparison with healthy volunteers In: United States. 117,21; discussion 122-123

17. Ueki K, Marukawa K, Nakagawa K, Yamamoto E (2002) Condylar and temporomandibular joint disc positions after mandibular osteotomy for prognathism. J Oral Maxillofac Surg 60:1424-1432, discussion 1432-4

18. Togashi M, Kobayashi T, Hasebe D, Funayama A, Mikami T, Saito I, Hayashi T, Saito C (2012) Effects of surgical orthodontic treatment for dentofacial deformities on signs and symptoms of temporomandibular joint

19. Nakata Y, Ueda HM, Kato M, Tabe H, Shikata-Wakisaka N, Matsumoto E, Koh M, Tanaka E, Tanne K (2007) Changes in stomatognathic function induced by orthognathic surgery in patients with mandibular prognathism. J Oral Maxillofac Surg 65:444-451

20. Kim YI, Cho BH, Jung YH, Son WS, Park SB (2011) Cone-beam computerized tomography evaluation of condylar changes and stability following two-jaw surgery: Le Fort I osteotomy and mandibular setback surgery with rigid fixation In: United States, Inc. 681-687

21. Mavili ME, Canter HI, Saglam-Aydinatay B (2009) Semirigid fixation of mandible and maxilla in orthognathic surgery: stability and advantages. Ann Plast Surg 63(4):396-403

22. Helkimo M (1974) Studies on function and dysfunction of the masticatory system. II. Index for. Sven Tandlak Tidskr 67:101-121

23. Fricton JR, Schiffman EL (1986) Reliability of a craniomandibular index. J Dent Res 65:1359-1364

\section{Submit your manuscript to a SpringerOpen ${ }^{\circ}$ journal and benefit from:}

- Convenient online submission

- Rigorous peer review

- Immediate publication on acceptance

- Open access: articles freely available online

- High visibility within the field

- Retaining the copyright to your article

Submit your next manuscript at $\gg$ springeropen.com 